
NonCommercial-NoDerivs 3.0 License (www.karger.com/OA-license), applicable to the online version of the article only. Distribution for non-commercial purposes only.

\title{
Onset Patterns and Initial Symptoms of Dementia with Lewy Bodies: Possible Pathophysiological Diversities Deduced from a SPECT Study
}

\author{
T. Fukui ${ }^{a} \quad$ K. Hori ${ }^{\text {b }} \quad$ H. Yoshimasu ${ }^{\text {b }}$ \\ ${ }^{a}$ Division of Neurology, Department of Internal Medicine, and ${ }^{b}$ Department of Psychiatry, \\ Showa University Northern Yokohama Hospital, Yokohama, Japan
}

\section{Key Words}

$\beta$ amyloid $\cdot$ Dementia onset patterns $\cdot$ Dementia with Lewy bodies $\cdot$ Initial dementia symptoms $\cdot$ Lewy bodies $\cdot$ SPECT

\begin{abstract}
Background/Aims: The aim of this study was to investigate onset patterns and initial symptoms in patients with dementia with Lewy bodies (DLB) and their association with SPECT findings. Methods: We studied 29 probable and 12 possible DLB patients. Onset was defined as 'acute' when symptoms (in various combinations) present within a few weeks or 'chronic' when a few symptoms present and progress during a longer period of time. Initial symptoms were dichotomized into 'cognitive' and 'non-cognitive'. We conducted voxel-to-voxel statistical analyses of SPECT, and uptake deviations from age-matched controls were depicted with Z-scores. Results: In acute patients, decreases were more apparent in the bilateral frontal and temporal lobes, whereas chronic patients showed decreases in the bilateral occipital, posterior cingulate and precuneal regions. Differences in the left frontal and left posterior cingulate were significant and those in the left temporal region showed a tendency toward significance. Patients with cognitive symptoms demonstrated more marked decreases in the bilateral temporal, parietal, occipital, cingulate and precuneal regions. Differences in the left parietal area reached significance and the total decreases were larger in patients with cognitive than non-cognitive symptoms, with a trend toward significance. Conclusions: The multiplicity of onset patterns and initial symptoms may possibly be based on pathophysiological diversities in DLB.
\end{abstract}

Copyright $\odot 2011$ S. Karger AG, Basel 


\section{Introduction}

In patients suffering from dementia with Lewy bodies (DLB), diagnostic precision has increased owing to more extensive use of the consensus diagnostic criteria [1] as well as surging awareness of this newcomer among the physicians. However, DLB is still one of the most under- or misdiagnosed dementias resulting in rather low sensitivity of the diagnostic criteria for DLB $(22-83 \%)$ in contrast with a much higher specificity $(79-100 \%)[2,3]$. Possible reasons for the difficulties in reaching a correct diagnosis of DLB may include a diversity of onset patterns and initial symptoms. Onset and progression are typically gradual and chronic, as suggested by the consensus criteria. In contrast, some DLB patients show multiple acute symptoms in various combinations and reach rather high levels of disability in a short time period. These DLB patients may pose diagnostic difficulty and are most likely misdiagnosed.

A related issue that may complicate the initial diagnosis of DLB may be the multiplicity of the presenting symptoms, ranging from only one symptom of cognitive, psychiatric, motoric or autonomic impairment to various symptom combinations. For instance, amnesia, appetite loss and fainting, although common in DLB, may appear mutually unrelated so that their combination hardly suggests DLB as a possible first-choice diagnosis.

Another pitfall in DLB diagnosis is the misinterpretation of one of the supportive features included in the diagnostic criteria, namely 'generalized low uptake with reduced occipital activity' on functional imaging [1]. In extreme cases, typical DLB patients without apparent uptake decreases in the occipital regions tend to be branded as 'DLB unlikely' only because of negative SPECT findings. It should be kept in mind that low uptake in the occipital areas is a feature distinguishing DLB from Alzheimer's disease (AD) [4-11], and that it is not a ubiquitous finding among patients with DLB $[9,12,13]$. Compared with normal controls, DLB patients may rather show lowered uptake in the frontal, parietal, temporal and thalamic regions [14]. Thus, 'occipital uptake decreases on SPECT' is not the gold standard for the diagnosis of DLB, and blind dependence on this supportive diagnostic feature may be misleading.

Because DLB shares a common pathological etiology with AD and Parkinson's disease (PD), it is understandable that the majority of functional imaging studies in DLB have targeted at the differential diagnosis of DLB from AD [4-12] or PD [14-16]. In contrast, only a minority of studies have focused upon the association between SPECT findings and specific functional impairments in DLB patients, namely motor symptoms [7, 17], visual hallucination [18] or cognitive decline [14,19]. Previously published studies suggested a link between hypoperfusion at the bilateral parietal $[20,21]$ or left temporal [20] regions and overall cognitive impairment in PD with dementia (PDD). Specifically, left parietal hypoperfusion was suggested to be associated with low Mini Mental State Examination (MMSE) scores [20], and hypoperfusion at the precuneus and inferior parietal regions with impairment in visuospatial maneuvers and perception $[11,19]$ in patients with DLB and PDD.

So far, SPECT uptake patterns in association with onset types (acute and chronic) and initial symptoms (cognitive and non-cognitive) of DLB have not yet been investigated. Thus, brain regions and pathophysiological features that may relate to these clinical diversities are unknown. We conducted this study firstly to summarize onset patterns and initial symptoms of DLB patients, secondly to correlate these clinical varieties with quantitative SPECT analyses, and thirdly to try to elucidate, although preliminarily, possible responsible pathophysiological features. Understanding their relationships may help to broaden our knowledge on DLB and strengthen the diagnostic power of the current criteria, especially in atypical cases. 


\section{Patients and Methods}

\section{Patients}

We recruited 54 consecutive patients who satisfied the consensus criteria for DLB in the period from 2005 to 2010. We further confirmed the diagnosis of DLB at the time of the present study on the basis of clinical courses after the first presentation. All 54 patients underwent brain MRI, ${ }^{99 \mathrm{~m} T c}$ ethylcysteinate dimer (ECD) SPECT and ${ }^{123}$ I-meta-iodobenzylguanidine (MIBG) myocardial scintigraphy as diagnostic procedures. Then, in the secondary analyses, we included only those who showed abnormalities on MIBG myocardial scintigraphy that are considered suggestive of DLB: heart/mediastinum $(\mathrm{H} / \mathrm{M})$ uptake ratio $<1.68$ and/or washout rate $>23.6 \%$ [22]. We adopted these rather stringent inclusion criteria in order to compensate for a lack of pathological confirmation. Brain MRI was used to exclude patients with apparent vascular lesions $(>3 \mathrm{~mm}$ ), idiopathic normal pressure hydrocephalus, subdural hematoma or brain tumor. Patients with a past/present history of alcoholism, drug abuse, brain trauma or debilitating diseases were excluded. Thirteen patients did not satisfy some of these requirements and were therefore excluded from the study, and 41 (29 probable and 12 possible) DLB patients were finally included in the investigation. This study was approved by the Ethics Committee of the Showa University Northern Yokohama Hospital.

\section{Definition of Onset Patterns and Initial Symptoms}

Clinical history data were obtained from reliable kin. Onset type was defined as 'acute' when cognitive, psychiatric, motoric or autonomic symptoms, frequently in various combinations, appeared in a rush in patients who had not shown any previous neurological or cognitive deficits and made them highly disabled within a few days or up to a few weeks. In contrast, onset was defined as 'chronic' when either a single or a couple of symptoms occurring one after another gradually progressed within a period of 6 months or more. Because patients were diagnosed with DLB according to the criteria, progressive cognitive decline (central feature) was noted during the follow-up period even when patients initially presented physical/autonomic symptoms. We did not include patients who showed a clinical course typical of PD for years before developing cognitive impairment (PDD).

We classified initial symptoms as cardinal and auxiliary: among multiple symptoms at presentation, the earliest and most prominent ones were designated as cardinal and those of lesser importance or severity as auxiliary. Cardinal initial symptoms were further dichotomized into 'cognitive' (cognitive and/or psychiatric) and 'non-cognitive' (motoric and/or autonomic). The rationale behind this classification is that cognitive and psychiatric, or physical and autonomic symptoms are often difficult to be delineated from each other. By and large, memory, visuospatial and executive impairments, and somnolence and cognitive fluctuations were classified as cognitive; hallucinations, delusions, misidentification syndrome, phantom boarders, mood and character changes and REM sleep behavioral disorder as psychiatric; parkinsonian symptoms represented by gait disturbance, easy falling, bradykinesia, rigidity and tremor as motoric, and loss of appetite, orthostatic hypotension, fainting and restless leg syndrome as autonomic. 'Ensuing' symptoms are those in favor of the diagnosis of DLB that appeared later during the follow-up period after the initial evaluation.

\section{Voxel-Based SPECT Analyses}

We analyzed the results of ${ }^{99 \mathrm{~m} T c-E C D}$ SPECT using two related voxel-based statistical programs, namely the Easy Z-score Imaging System (eZIS) [23] and the voxel-based Stereotactic Extraction Estimation Program (vbSEE) [24]. The eZIS program processes the original SPECT data so that the brain morphology is anatomically remodeled and brain areas were defined according to Talairach and Tournoux normal brain. Then, voxel-by-voxel uptake 
Fukui et al.: Onset Patterns, Initial Symptoms and Related SPECT Findings in DLB

Table 1. Patient demography and the results of MIBG myocardial scintigraphy

\begin{tabular}{|c|c|c|c|c|c|c|c|c|c|c|c|c|}
\hline & $\begin{array}{l}\text { Age } \\
\text { years }\end{array}$ & $\mathrm{p}$ & $\begin{array}{l}\text { Males } \\
\%\end{array}$ & $\mathrm{p}$ & $\begin{array}{l}\text { Duration } \\
\text { months }\end{array}$ & $\mathrm{p}$ & Early H/M & $\mathrm{p}$ & Late $\mathrm{H} / \mathrm{M}$ & $\mathrm{p}$ & $\begin{array}{l}\text { Washout } \\
\text { rates }\end{array}$ & $\mathrm{p}$ \\
\hline $\begin{array}{l}\text { Acute onset }(n=21) \\
\text { Chronic onset }(n=20)\end{array}$ & $\begin{array}{l}77.5 \pm 10.7 \\
76.3 \pm 5.1\end{array}$ & 0.64 & $\begin{array}{l}43 \\
50\end{array}$ & 0.65 & $\begin{array}{r}2.2 \pm 1.8 \\
21.0 \pm 9.4\end{array}$ & 0.0005 & $\begin{array}{l}1.69 \pm 0.36 \\
1.57 \pm 0.27\end{array}$ & 0.22 & $\begin{array}{l}1.61 \pm 0.43 \\
1.50 \pm 0.33\end{array}$ & 0.34 & $\begin{array}{l}40.3 \pm 9.7 \\
41.0 \pm 8.7\end{array}$ & 0.80 \\
\hline $\begin{array}{l}\text { Cognitive }(n=31) \\
\text { Non-cognitive }(n=10)\end{array}$ & $\begin{array}{l}76.3 \pm 9.0 \\
79.5 \pm 5.3\end{array}$ & 0.26 & $\begin{array}{l}45 \\
50\end{array}$ & 0.79 & $\begin{array}{c}13.0 \pm 12.2 \\
6.3 \pm 7.6\end{array}$ & 0.14 & $\begin{array}{l}1.67 \pm 0.33 \\
1.53 \pm 0.25\end{array}$ & 0.33 & $\begin{array}{l}1.62 \pm 0.40 \\
1.33 \pm 0.21\end{array}$ & 0.01 & $\begin{array}{l}38.6 \pm 9.3 \\
46.7 \pm 5.5\end{array}$ & 0.09 \\
\hline
\end{tabular}

changes were compared with data obtained from 283 normal age-matched controls and shown qualitatively by a spectrum of colors on the morphologically normalized brain [23]. In the next step, we used the vbSEE program to quantify SPECT data that had been processed by the eZIS program as described. Specifically, the vbSEE program calculated the percentage of voxels that showed uptake decreases of 2 standard deviations or more from the average of age-matched normal controls (designated as extension) in a specific brain area, and the average of $Z$-scores of these voxels (severity). Then we used their products (extension $\times$ severity) as the indices of uptake reduction representing the frontal, temporal, parietal and occipital lobes, anterior and posterior cingulate, and precuneus, as defined according to the Talairach coordinate system.

\section{Statistics}

We used SPSS version 17.0J for statistical analyses. As Z-scores are defined to have a normal distribution, we used Student's t test to compare local Z-scores and a logistic regression to seek the loci of hypoperfusion that are the most relevant to onset patterns (acute or chronic) or initial symptoms (cognitive or non-cognitive). A p value $<0.05$ represented statistical significance.

\section{Results}

\section{Patient Demography and MIBG Myocardial Scintigraphy}

Patient demography and results of MIBG myocardial scintigraphy are summarized in table 1. Age and gender distribution were comparable between the groups defined by either onset types or initial symptoms. Duration of illness, defined as the time span (months) between the emergence of the first symptoms and presentation to the hospital, was significantly shorter for the acute- than chronic-onset group. The cognitive group showed a longer duration, although non-significantly, than the non-cognitive group.

The indices of MIBG myocardial scintigraphy (H/M ratios and washout ratios) did not differ between patient groups with different onset patterns. In the non-cognitive group, late $\mathrm{H} / \mathrm{M}$ ratios were significantly smaller and the washout ratios were larger with a tendency toward significance compared with the cognitive group. Early H/M ratios were also lower in the non-cognitive group, although non-significantly. More apparent abnormalities on MIBG myocardial scintigraphy in the non-cognitive group may be reflective of inclusion of autonomic patients in this group.

Onset Patterns and Initial Symptoms

Table 2 shows the diagnoses (probable vs. possible), onset patterns (acute vs. chronic), types of initial symptoms (cognitive and non-cognitive) and their details (cardinal vs. auxil- 
Table 2. Initial and ensuing symptoms

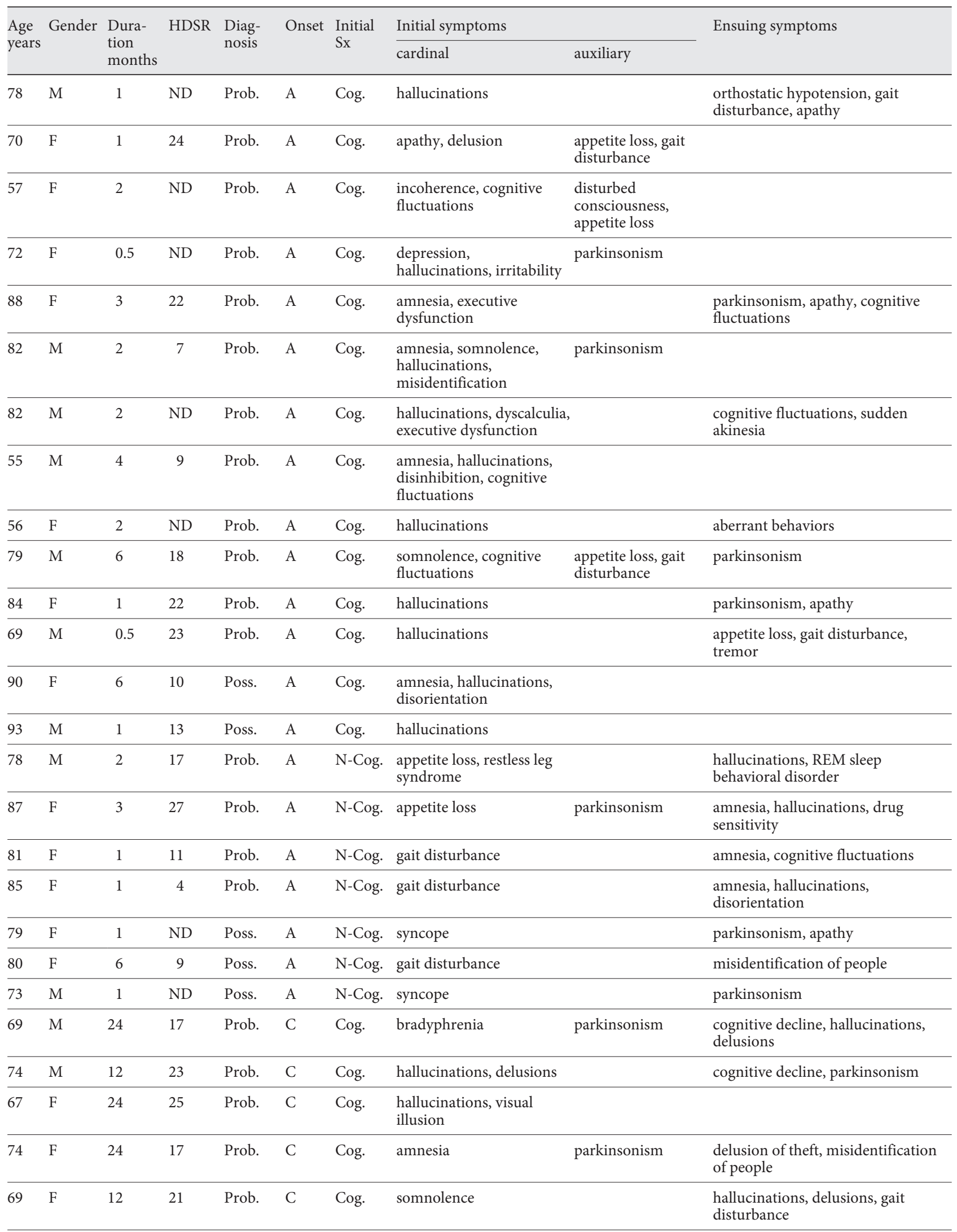


Table 2 (continued)

\begin{tabular}{|c|c|c|c|c|c|c|c|c|c|}
\hline \multirow{2}{*}{$\begin{array}{l}\text { Age } \\
\text { years }\end{array}$} & \multirow{2}{*}{ Gender } & \multirow{2}{*}{$\begin{array}{l}\text { Dura- } \\
\text { tion } \\
\text { months }\end{array}$} & \multirow{2}{*}{ HDSR } & \multirow{2}{*}{$\begin{array}{l}\text { Diag- } \\
\text { nosis }\end{array}$} & \multirow[t]{2}{*}{ Onset } & \multirow{2}{*}{$\begin{array}{l}\text { Initial } \\
\text { Sx }\end{array}$} & \multicolumn{2}{|l|}{ Initial symptoms } & \multirow[t]{2}{*}{ Ensuing symptoms } \\
\hline & & & & & & & cardinal & auxiliary & \\
\hline 78 & $\mathrm{~F}$ & 24 & 22 & Prob. & $\mathrm{C}$ & Cog. & amnesia, depression & & gait disturbance \\
\hline 72 & M & 12 & 14 & Prob. & $\mathrm{C}$ & Cog. & apathy & & hallucinations, parkinsonism \\
\hline 82 & $\mathrm{~F}$ & 36 & 11 & Prob. & $\mathrm{C}$ & Cog. & amnesia & & $\begin{array}{l}\text { hallucinations, cognitive } \\
\text { fluctuations, parkinsonism }\end{array}$ \\
\hline 78 & M & 36 & 14 & Prob. & $\mathrm{C}$ & Cog. & amnesia & & $\begin{array}{l}\text { misidentification syndrome, } \\
\text { gait disturbance }\end{array}$ \\
\hline 83 & M & 12 & 13 & Prob. & $\mathrm{C}$ & Cog. & $\begin{array}{l}\text { amnesia, hallucinations, } \\
\text { delusions, irritability }\end{array}$ & & \\
\hline 79 & $\mathrm{~F}$ & 12 & 22 & Poss. & $\mathrm{C}$ & Cog. & amnesia & & \\
\hline 72 & M & 36 & 4 & Poss. & $\mathrm{C}$ & Cog. & amnesia & parkinsonism & \\
\hline 80 & $\mathrm{~F}$ & 24 & ND & Poss. & $\mathrm{C}$ & Cog. & $\begin{array}{l}\text { amnesia, hallucinations, } \\
\text { delusions }\end{array}$ & & \\
\hline 77 & $\mathrm{~F}$ & 12 & 16 & Poss. & $\mathrm{C}$ & Cog. & amnesia & & $\begin{array}{l}\text { cognitive fluctuations, gait } \\
\text { disturbance }\end{array}$ \\
\hline 79 & M & 36 & 21 & Poss. & $\mathrm{C}$ & Cog. & amnesia & & \\
\hline 82 & $\mathrm{~F}$ & 12 & 1 & Poss. & $\mathrm{C}$ & Cog. & amnesia, inattention & & hallucinations, visual illusion \\
\hline 79 & $\mathrm{~F}$ & 24 & 27 & Poss. & $\mathrm{C}$ & Cog. & $\begin{array}{l}\text { amnesia, executive } \\
\text { dysfunction, personality } \\
\text { change }\end{array}$ & & parkinsonism \\
\hline 69 & M & 12 & 26 & Prob. & $\mathrm{C}$ & N-Cog. & parkinsonism & & depression, hallucinations, delusions \\
\hline 81 & M & 24 & ND & Prob. & $\mathrm{C}$ & N-Cog. & hypotension & $\begin{array}{l}\text { cognitive } \\
\text { fluctuations }\end{array}$ & amnesia, apathy, parkinsonism \\
\hline 81 & $\mathrm{M}$ & 12 & 21 & Prob. & $\mathrm{C}$ & N-Cog. & gait disturbance & & amnesia, hallucinations \\
\hline
\end{tabular}

Patient backgrounds, diagnoses, onset patterns [acute (A) and chronic (C)], classification based on the initial symptoms (Sx): [cognitive/psychiatric (Cog.) and motoric/autonomic (N-Cog.)] and contents of the initial and ensuing symptoms in all 41 patients are shown. ND = Not done; Poss. $=$ possible; Prob. $=$ probable.

iary), ensuing symptoms, duration of illness and the scores of the revised Hasegawa Dementia Scale (HDSR) at the first evaluation, a short cognitive test similar to the MMSE with a total score of 30 . We could not administer the HDSR to some patients because of fluctuating mental clarity. The average HDSR scores did not differ between acute (mean \pm SD: $15.4 \pm 7.3$ ) and chronic $(17.5 \pm 7.2)$ groups $(\mathrm{p}=0.44$; Mann-Whitney $\mathrm{U}$ test), or cognitive (16.6 \pm 6.9$)$ and non-cognitive $(16.4 \pm 8.8)$ groups $(\mathrm{p}=0.96)$, indicating that global cognition was ubiquitously impaired at the time of evaluation regardless of onset patterns and initial symptoms.

Table 3 shows the frequencies of initial and ensuing symptoms of acute or chronic, and cognitive or non-cognitive patients. The frequency of symptoms was defined as the percentage of each symptom among those grouped as either cardinal, auxiliary or ensuing. In cognitive groups, hallucinations (33\%), executive impairment (15\%), somnolence (15\%), amnesia (13\%) and cognitive fluctuations (13\%) constituted the most frequent symptoms in the acuteonset patients, whereas amnesia (41\%) was the most common together with hallucinations (17\%) and delusions (10\%) in chronic-onset patients. For auxiliary symptoms in the cognitive groups, parkinsonism and appetite loss were prevalent in acute-onset patients. All patients with eating problems underwent meticulous gastrointestinal investigations that revealed no organic abnormalities. Appetite loss did not represent negativism toward eating and thus was 
Fukui et al.: Onset Patterns, Initial Symptoms and Related SPECT Findings in DLB

Table 3. Contents and frequency of cognitive, psychiatric, motoric and autonomic symptoms

\begin{tabular}{|c|c|c|c|c|c|c|c|c|c|c|c|c|}
\hline \multirow[t]{2}{*}{ Symptoms } & \multicolumn{3}{|c|}{ Acute cognitive } & \multicolumn{3}{|c|}{ Chronic cognitive } & \multicolumn{3}{|c|}{ Acute non-cognitive } & \multicolumn{3}{|c|}{ Chronic non-cognitive } \\
\hline & cardinal & auxiliary & ensuing & cardinal & auxiliary & ensuing & cardinal & auxiliary & ensuing & cardinal & auxiliary & ensuing \\
\hline Amnesia & $13 \%$ & & & $41 \%$ & & & & & $25 \%$ & & & $25 \%$ \\
\hline Executive impairment & $15 \%$ & & & & & $9 \%$ & & & & & & \\
\hline Dyscalculia & $3 \%$ & & & & & & & & & & & \\
\hline Disorientation & $3 \%$ & & & & & & & & $6 \%$ & & & \\
\hline Somnolence & $15 \%$ & & & $3 \%$ & & & & & & & & \\
\hline Cognitive fluctuation & $13 \%$ & $14 \%$ & $19 \%$ & $6 \%$ & $25 \%$ & $9 \%$ & & & $6 \%$ & & $100 \%$ & \\
\hline \multicolumn{13}{|l|}{ Psychiatric } \\
\hline Hallucinations & $33 \%$ & & & $17 \%$ & & $26 \%$ & & & $25 \%$ & & & $25 \%$ \\
\hline Delusions & $3 \%$ & & & $10 \%$ & & $13 \%$ & & & & & & $13 \%$ \\
\hline Misidentification & $3 \%$ & & & & & $9 \%$ & & & $6 \%$ & & & \\
\hline Incoherence & $3 \%$ & & & & & & & & & & & \\
\hline Depression & $3 \%$ & & & $3 \%$ & & & & & & & & $13 \%$ \\
\hline Irritability & $3 \%$ & & & $3 \%$ & & & & & & & & \\
\hline Disinhibition & $3 \%$ & & & & & & & & & & & \\
\hline Character changes & & & & $3 \%$ & & & & & & & & \\
\hline Aberrant behaviors & & & $6 \%$ & & & & & & & & & \\
\hline REM sleep behavioral disorder & & & & & & & & $6 \%$ & & & & \\
\hline \multicolumn{13}{|l|}{ Motoric } \\
\hline Parkinsonism & & $43 \%$ & $31 \%$ & & $75 \%$ & $35 \%$ & $44 \%$ & $13 \%$ & $12 \%$ & $67 \%$ & & $13 \%$ \\
\hline \multicolumn{13}{|l|}{ Autonomic } \\
\hline Appetite loss & & $43 \%$ & $6 \%$ & & & & $22 \%$ & & & & & \\
\hline Othostatic hypotension/syncope & & $6 \%$ & & & & & $22 \%$ & & & $33 \%$ & & \\
\hline Restless leg syndrome & & & & & & & $11 \%$ & & & & & \\
\hline Drug hypersensitivity & & & & & & & & & $6 \%$ & & & \\
\hline
\end{tabular}

interpreted as a sign of autonomic dysfunction. In chronic-onset cognitive patients, parkinsonism and cognitive fluctuations were most likely to accompany the cardinal cognitive/ psychiatric symptoms.

In the non-cognitive group, parkinsonism was the most frequent symptom regardless of the onset types. Autonomic disturbances were various (appetite loss, orthostatic hypotension/syncope and restless leg syndrome) and more frequent in acute- than chronic-onset patients, in whom orthostatic hypotension/syncope was the only autonomic impairment. In both onset types, amnesia (25\%) and hallucinations (25\%) may be later added to the initial clinical pictures. Non-cognitive patients with acute onset may further experience disorientation, cognitive fluctuation, misidentification syndrome and apathy (6\% for each). In contrast, compared with patients with acute onset, patients with chronic onset may more often (13\%) develop psychiatric problems such as delusions, apathy and depression.

\section{Quantitative SPECT Analyses}

Figure 1 shows uptake reductions, expressed by 'extension $\times$ severity' calculated by the vbSEE program for each brain area under consideration in all 41 DLB patients regardless of the onset patterns and initial symptoms. Given DLB patients were compared with age-matched normal controls, DLB patients demonstrated rather diffuse uptake decreases that were not necessarily restricted to the occipital areas. Contrarily, uptake decreases appeared rather milder in the occipital than in the frontal, parietal, anterior cingulate or precuneal regions.

Acute versus Chronic Onset. The acute-onset group (cognitive and non-cognitive groups combined) showed more pronounced uptake decreases in bilateral frontal and temporal 
Fig. 1. Uptake reductions (extension $\times$ severity) in comparison with age-matched normal controls for each brain area in all 41 DLB patients. Note that uptake reductions are rather ubiquitous and not restricted to the occipital lobes (see text for the technical comments). Front. $=$ Frontal lobes; Temp. = temporal lobes; Par. = parietal lobes; Occ. $=$ occipital lobes; Ant. Cing. = anterior cingulate; Post. Cing. = posterior cingulate; Prec. $=$ precuneus.

Fig. 2. Uptake reductions in acute- and chronic-onset patients. In acute-onset patients, reductions are more frequent in the frontal and temporal lobes, whereas in chronic-onset patients reductions are more frequent in the occipital lobes, posterior cingulate and precuneus. Abbreviations are the same as in figure 1 .
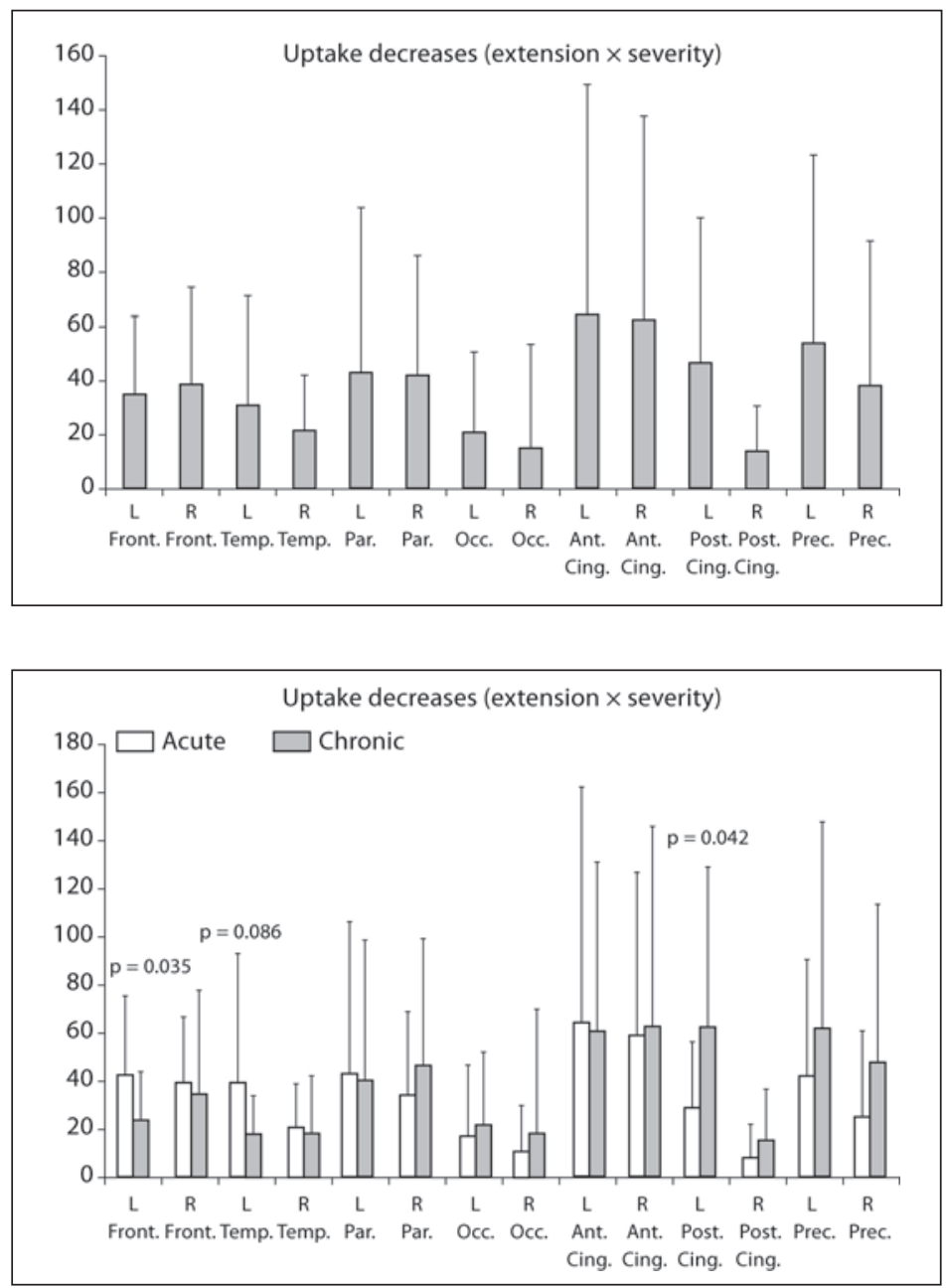

lobes whereas the chronic group showed reductions of a higher degree in the bilateral occipital, posterior cingulate and precuneal regions (fig. 2). Among them, uptake reductions in the left frontal lobe (acute $42.3 \pm 33.0$, chronic $23.7 \pm 19.9 ; \mathrm{p}=0.035$ ) were significantly severer and those in the left temporal lobe tended to be lager in the acute-onset patients (acute $39.5 \pm 53.2$, chronic $17.8 \pm 15.5 ; \mathrm{p}=0.086$ ) whereas decreases at the left posterior cingulate (acute $28.4 \pm 27.8$, chronic $62.6 \pm 66.3 ; \mathrm{p}=0.042$ ) were significantly larger in the chroniconset patients. A logistic regression revealed that hypoperfusion at the left posterior cingulate was a significant determinant of chronicity [odds ratio $(\mathrm{OR})=1.02, \mathrm{p}=0.049$, explaining $11.0 \%$ of variance].

Cognitive versus Non-Cognitive. The total uptake decrease in the cognitive group (544.3 $\pm 302.8)$ was larger than that of the non-cognitive group (369.1 \pm 182.5$)$, and the intergroup difference showed a trend toward significance $(\mathrm{p}=0.093)$. Decreases in almost all brain areas under consideration were also more profound in the cognitive than non-cognitive group. Differences in the left parietal lobes (cognitive $49.2 \pm 66.4$, non-cognitive $19.6 \pm 21.3$ ) reached statistical significance ( $\mathrm{p}=0.37$; fig. 3 ). Although barely significant on a logistic regression, hypoperfusion at the left parietal $(\mathrm{OR}=1.17, \mathrm{p}=0.053)$, left precuneus $(\mathrm{OR}=1.13$, $\mathrm{p}=0.10)$ and right anterior cingulate $(\mathrm{OR}=1.13, \mathrm{p}=0.08)$ was a possible determinant of cognitive/psychiatric onset. 
Fig. 3. Uptake reductions are generally more marked in cognitive than in non-cognitive patients. The difference in the left parietal lobe reached statistical significance. Abbreviations are the same as in figure 1 .

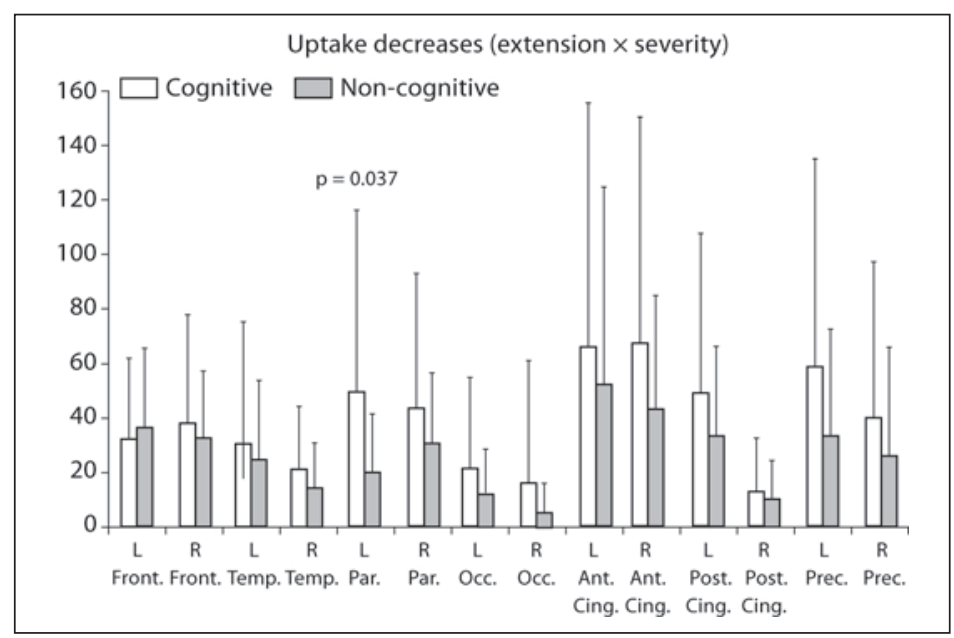

\section{Discussion}

Firstly, this study showed that DLB patients are likely to present a wide range of symptoms at the initial stage both in an acute and chronic fashion. Secondly, voxel-based statistical SPECT analyses showed that uptake decreases in DLB patients compared with age-matched normal controls were rather diffusely distributed, involving both the anterior and posterior brain areas and not necessarily restricted to the occipital areas. With regard to onset modalities, left frontal and temporal hypoperfusion appeared associated significantly with acute onset, and hypoperfusion in the left posterior cingulate with chronic onset. Thirdly, SPECT analyses also suggested that DLB patients presenting cognitive (cognitive/psychiatric) rather than non-cognitive (motoric/autonomic) symptoms in the initial stage showed more prominent uptake reduction in almost all brain areas, with an accentuation in the left parietal areas. These results may shed light on the association between the wide range of clinical presentations of DLB and possible pathophysiological variance represented on SPECT.

\section{Onset Patterns}

Symptoms emerged rather rapidly in 21 patients but progressed slowly in the remaining 20. The consensus criteria state that the central features are 'progressive' although the speed of exacerbation is not specified. It may be generally understood that symptoms of DLB progress chronically although faster than $\mathrm{PD}$ and $\mathrm{AD}$. Thus, physicians may be confronted with diagnostic difficulties when facing DLB patients presenting various combinations of acute symptoms within a mean of 2 months, as shown by the acute-onset group. In this situation, DLB may be confused with infectious, toxic, traumatic, vascular or acute psychiatric disorders, or even Creutzfeldt-Jakob disease.

Using the quantitative SPECT analyses, we demonstrated that acute-onset patients showed uptake decreases primarily in the anterior part of the brain, specifically the left frontal and temporal lobes, while the chronic-onset patients showed hypoperfusion in the posterior brain areas, specifically the left posterior cingulate regions. Since the total uptake decreases were comparable between the acute $(472.0 \pm 252.5)$ and chronic $(486.5 \pm 335.1)$ groups ( $\mathrm{p}=0.77$; Mann-Whitney $\mathrm{U}$ test), it may be deduced that the determinant factor of acute-type onset is the distribution of perfusion reduction and not the overall severity.

Then what constitutes the pathological and functional etiology of acute- and chroniconset modalities? Based on the results from the present study, we hypothesized that patho- 
logical burdens of DLB (both Lewy bodies, LB, and beta amyloid, A $\beta$ ) accentuated in the anterior part of the brain lead to acute onset whereas those rather restricted to the posterior part lead to chronic onset.

Pathological investigations in DLB demonstrated that LB pathologies dominate in the anterior brain areas (amygdala, cingulate, temporal, entorhinal and parahippocampal) and are rare in the parietal and occipital areas $[25,26]$. On the other hand, amyloid pathologies detected by ${ }^{11} \mathrm{C}-\mathrm{PiB}\left({ }^{11} \mathrm{C}\right.$-Pittsburgh compound $\left.\mathrm{B}\right) \mathrm{PET}$ in an autopsy-confirmed DLB patient were distributed in the temporal, insular and orbital frontal cortices as well as posterior cingulate, precuneus and posterior parietal regions [26]. With respect to cognitive impairment in DLB, both $A \beta$ and LB pathologies are known to contribute independently [27]. When taken together, DLB patients with denser LB pathologies may have more frontally distributed functional impairment depicted on SPECT that associates with acute onset and exacerbation. Conversely, chronic-onset DLB patients may have relatively denser A $\beta$ pathologies in the posterior brain areas. As with $\mathrm{AD}$ patients, these $\mathrm{DLB}$ patients may progress rather slowly compared with LB pathology-dominant patients. However, these assumptions are apparently beyond the scope of this investigation and need a correlative study between SPECT patterns and pathology.

There are some alternative interpretations for these different onset types. Generally, frontal lobe-related symptoms (executive dysfunction, incoherence, depression, apathy, irritability and disinhibition) and temporal lobe-related symptoms (visual hallucinations) [25] may be more alarming to those around the patient and alert them to seek earlier medical consultation. In contrast, chronically progressive amnesia that was prevalent in the chroniconset group (table 3) may be often taken as granted for the elderly and may allow more time before the first medical consultation is sought.

\section{Initial Symptoms}

We showed that onset with cognitive/psychiatric symptoms was associated with more extensive and profound hypoperfusion than non-cognitive onset. Given loads of pathological changes correlate with hypoperfusion on SPECT [20], we assume that cognitive/psychiatric symptoms are likely to be the initial symptom(s) when both $L B$ and $A \beta$ loads are generally heavier. Significant uptake decreases in the left parietal lobe in the cognitive group may reinforce the previous findings that parietal hypoperfusion, especially on the left, correlates with global cognitive impairment in PD [21] and lower MMSE scores in PDD [20]. In addition, hypoperfusion at the precuneus is associated with visual cognitive impairment $[11,19]$. The present study further expands this knowledge by showing that generalized hypoperfusion with an accentuation at parietal and precuneus regions, and possibly the right anterior cingulate may be associated with onset of cognitive/psychiatric symptoms. Conversely, motor/autonomic symptoms may initially appear when the pathological changes are more localized and/or milder. In fact, parkinsonism was associated with hypoperfusion relatively confined to the frontal lobes $[7,17]$.

Lastly, this study suffers from some limitations. We included only a small number of DLB patients $(\mathrm{n}=41)$ because we required brain MRI, SPECT and MIBG myocardial scintigraphy to be performed in all patients in order to compensate for the lack of pathological confirmation. We preferred to adopt these rather stringent measures to be able to exclude clinically diseases such as $\mathrm{AD}$, progressive supranuclear palsy or multisystem atrophy that may initially mimic clinical pictures of DLB. Conversely, the rather strict entry criteria may lower the sensitivity of the diagnostic power and cause some patient selection bias.

The second limitation is associated with the dichotomization of the cardinal initial symptoms into cognitive/psychiatric and motoric/autonomic. Ideally, comparisons should be made among four groups, namely cognitive, psychiatric, motoric and autonomic groups, 
or even eight groups when the onset patterns are also considered. However, cognitive and psychiatric or motoric and autonomic symptoms often coexisted, and their borders are often vague. Furthermore, the total number of patients being small, too fine a classification would have made statistical comparisons difficult.

The third difficulty may be associated with the definition of onset types. The cutoff of 6 months was arbitrarily determined on the factual observation that most acute-onset patients develop all symptoms within 6 months, mostly within a few days to weeks, and in most chronic-onset patients it took $>6$ months, mostly $1-3$ years, for symptoms to develop.

In spite of all these shortcomings, this study provided more insights into the onset patterns, initial symptoms and related possible pathophysiology in DLB patients.

\section{Disclosure Statement}

No conflict of interest declared.

\section{References}

-1 McKeith IG, Dickson DW, Lowe J, Emre M, O’Brien JT, Feldman H, Cummings J, Duda JE, Lippa C, Perry EK, Aarsland D, Arai H, Ballard CG, Boeve B, Burn DJ, Costa D, Del Ser T, Dubois B, Galasko D, Gauthier S, Goetz CG, Gomez-Tortosa E, Halliday G, Hansen LA, Hardy J, Iwatsubo T, Kalaria RN, Kaufer D, Kenny RA, Korczyn A, Kosaka K, Lee VM, Lees A, Litvan I, Londos E, Lopez OL, Minoshima S, Mizuno Y, Molina JA, Mukaetova-Ladinska EB, Pasquier F, Perry RH, Schulz JB, Trojanowski JQ, Yamada M, Consortium on DLB: Diagnosis and management of dementia with Lewy bodies: third report of the DLB Consortium. Neurology 2005;65:1863-1872.

-2 Luis CA, Barker WW, Gajaraj K, Harwood D, Petersen R, Kashuba A, Waters C, Jimison P, Pearl G, Petito C, Dickson D, Duara R: Sensitivity and specificity of three clinical criteria for dementia with Lewy bodies in an autopsy-verified sample. Int J Geriatr Psychiatry 1999;14:526-533.

-3 McKeith IG, Ballard CG, Perry RH, Ince PG, O’Brien JT, Neill D, Lowery K, Jaros E, Barber R, Thompson P, Swann A, Fairbairn AF, Perry EK: Prospective validation of consensus criteria for the diagnosis of dementia with Lewy bodies. Neurology 2000;54:1050-1058.

-4 Goto H, Ishii K, Uemura T, Miyamoto N, Yoshikawa T, Shimada K, Ohkawa S: Differential diagnosis of dementia with Lewy bodies and Alzheimer disease using combined MR imaging and brain perfusion single-photon emission tomography. AJNR Am J Neuroradiol 2010;31:720-725.

-5 Colloby SJ, Taylor JP, Firbank MJ, McKeith IG, Williams ED, O’Brien JT: Covariance ${ }^{99 \mathrm{~m} T c-e x a-}$ metazime SPECT patterns in Alzheimer's disease and dementia with Lewy bodies: utility in differential diagnosis. J Geriatr Psychiatry Neurol 2010;23:54-62.

-6 Ishii K, Kanda T, Uemura T, Miyamoto N, Yoshikawa T, Shimada K, Ohkawa S, Minoshima S: Computer-assisted diagnostic system for neurodegenerative dementia using brain SPECT and 3D-SSP. Eur J Nucl Med Mol Imaging 2009;36:831-840.

-7 Tateno M, Utsumi K, Kobayashi S, Takahashi A, Saitoh M, Morii H, Fujii K, Teraoka M: Usefulness of a blood flow analyzing program 3DSRT to detect occipital hypoperfusion in dementia with Lewy bodies. Prog Neuropsychopharmacol Biol Psychiatry 2008;32:1206-1209.

-8 Chang CC, Liu JS, Chang YY, Chang WN, Chen SS, Lee CH, Shimizu S, Hanyu H, Hirao K, Sato T, Iwamoto T, Koizumi K: Value of analyzing deep gray matter and occipital lobe perfusion to differentiate dementia with Lewy bodies from Alzheimer's disease. Ann Nucl Med 2008;22:911-916.

-9 Shimizu S, Hanyu H, Hirao K, Sato T, Iwamoto T, Koizumi K: Value of analyzing deep gray matter and occipital lobe perfusion to differentiate dementia with Lewy bodies from Alzheimer's disease. Ann Nucl Med 2008;22:911-916. 
-10 Hanyu H, Shimizu S, Hirao K, Kanetaka H, Iwamoto T, Chikamori T, Usui Y, Yamashina A, Koizumi K, Abe K: Comparative value of brain perfusion SPECT and [ $\left.{ }^{123} \mathrm{I}\right] \mathrm{MIBG}$ myocardial scintigraphy in distinguishing between dementia with Lewy bodies and Alzheimer's disease. Eur J Nucl Med Mol Imaging 2006;33:248-253.

-11 Colloby SJ, Fenwick JD, Williams ED, Paling SM, Lobotesis K, Ballard C, McKeith I, O’Brien JT: A comparison of ${ }^{99 \mathrm{~m}} \mathrm{Tc}-\mathrm{HMPAO}$ SPET changes in dementia with Lewy bodies and Alzheimer's disease using statistical parametric mapping. Eur J Nucl Med Mol Imaging 2002;29:615-622.

-12 Lobotesis K, Fenwick JD, Phipps A, Ryman A, Swann A, Ballard C, McKeith IG, O’Brien JT: Occipital hypoperfusion on SPECT in dementia with Lewy bodies but not AD. Neurology 2001;56:643-649.

-13 Inui Y, Toyama H, Manabe Y, Sato T, Sarai M, Kosaka K, Iwata N, Katada K: Evaluation of probable or possible dementia with Lewy bodies using ${ }^{123} \mathrm{I}$-IMP brain perfusion SPECT, ${ }^{123} \mathrm{I}-\mathrm{MIBG}$, and ${ }^{99 \mathrm{~m}} \mathrm{Tc}-$ MIBI myocardial SPECT. J Nucl Med 2007;48:1641-1650.

14 Chang CC, Liu JS, Chang YY, Chang WN, Chen SS, Lee CH: ${ }^{99 m}$ Tc-ethyl cysteinate dimer brain SPECT findings in early stage of dementia with Lewy bodies and Parkinson's disease patients: a correlation with neuropsychological tests. Eur J Neurol 2008;15:61-65.

- 15 Mito Y, Yoshida K, Yabe I, Makino K, Hirotani M, Tashiro K, Kikuchi S, Sasaki H: Brain 3D-SSP SPECT analysis in dementia with Lewy bodies, Parkinson's disease with and without dementia, and Alzheimer's disease. Clin Neurol Neurosurg 2005;107:396-403.

-16 Kasama S, Tachibana H, Kawabata K, Yoshikawa H: Cerebral blood flow in Parkinson's disease, dementia with Lewy bodies, and Alzheimer's disease according to three-dimensional stereotactic surface projection imaging. Dement Geriatr Cogn Disord 2005;19:266-275.

-17 Takahashi R, Ishii K, Shimada K, Ohkawa S, Nishimura Y: Hypoperfusion of the motor cortex associated with parkinsonism in dementia with Lewy bodies. J Neurol Sci 2010;288:88-91.

$\checkmark 18$ Mori T, Ikeda M, Fukuhara R, Nestor PJ, Tanabe H: Correlation of visual hallucinations with occipital rCBF changes by donepezil in DLB. Neurology 2006;66:935-937.

19 Firbank MJ, Colloby SJ, Burn DJ, McKeith IG, O’Brien JT: Regional cerebral blood flow in Parkinson's disease with and without dementia. Neuroimage 2003;20:1309-1319.

-20 Sawada H, Udaka F, Kameyama M, Seriu N, Nishinaka K, Shindou K, Kodama M, Nishitani N, Okumiya K: SPECT findings in Parkinson's disease associated with dementia. J Neurol Neurosurg Psychiatry 1992;55:960-963.

-21 Tachibana H, Tomino Y, Kawabata K, Sugita M, Fukuchi M: Twelve-month follow-up study of regional cerebral blood flow in Parkinson's disease. Dementia 1995;6:89-93.

-22 Yoshita M, Taki J, Yokoyama K, Noguchi-Shinohara M, Matsumoto Y, Nakajima K, Yamada M: Value of ${ }^{123}$ I-MIBG radioactivity in the differential diagnosis of DLB from AD. Neurology 2006;66: 1850-1854.

-23 Matsuda H, Mizumura S, Soma T, Takemura N: Conversion of brain SPECT images between different collimators and reconstruction processes for analysis using statistical parametric mapping. Nucl Med Commun 2004;25:67-74.

-24 Mizumura S, Kumita S, Cho K, Ishihara M, Nakajo H, Toba M, Kumazaki T: Development of quantitative analysis method for stereotactic brain image: assessment of reduced accumulation in extent and severity using anatomical segmentation. Ann Nucl Med 2003;17:289-295.

-25 Harding AJ, Broe GA, Halliday GM: Visual hallucinations in Lewy body disease relate to Lewy bodies in the temporal lobe. Brain 2002;125:391-403.

-26 Bacskai BJ, Frosch MP, Freeman SH, Raymond SB, Augustinack JC, Johnson KA, Irizarry MC, Klunk WE, Mathis CA, Dekosky ST, Greenberg SM, Hyman BT, Growdon JH: Molecular imaging with Pittsburgh compound B confirmed at autopsy: a case report. Arch Neurol 2007;64:431-434.

-27 Harding AJ, Halliday GM: Cortical Lewy body pathology in the diagnosis of dementia. Acta Neuropathol 2001;102:355-363. 